\title{
The Auxiliary Role of Hematological Parameters in Diagnosing Localized Germ Cell Testicular Tumor
}

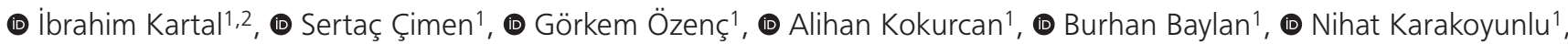 \\ (D) Orhan Yiğitbaşı ${ }^{1}$, (D) Fatih Yalçınkaya ${ }^{1}$ \\ ${ }^{1}$ University of Health Sciences Turkey, Dışkapı Yıldırım Beyazıt Training and Research Hospital, Clinic of Urology, Ankara, Turkey \\ ${ }^{2}$ Kütahya University of Health Sciences Turkey, Evliya Çelebi Training and Research Hospital, Clinic of Urology, Kütahya, Turkey
}

\begin{abstract}
Objective: There is a lack of information about the relationship between germ cell testicular tumors and hematological parameters commonly used in other tumors. In this study, it was aimed to determine the value of hematological parameters used in other malignancies in the diagnosis of localized germ cell testicular cancer. Materials and Methods: Hematological parameters between patients who underwent radical orchiectomy with a pre-diagnosis of localized germ cell testicular tumor and those who underwent varicocelectomy in the same period as the control group between January 2015 and March 2019 in our clinic were compared to determine the diagnostic value of hematological parameters in testicular tumor.

Results: The mean age of 39 patients diagnosed as having localized testicular tumor was 33 years. While seminoma was detected in 17 patients, non-seminomatous germ cell tumors were detected in 22 patients. In the assessment of preoperative blood samples; neutrophil count (5.6 vs $4.1, p \leq 0.001)$, neutrophil percentage $(65.8$ vs $57.4, p \leq 0.001)$ and neutrophil/lymphocyte ratio ( 2.6 vs $1.8, p \leq 0.001)$ were significantly higher, while lymphocyte ratio was significantly lower ( 25.3 vs $31.4, p \leq 0.001)$ in patients with testicular tumor than in the control group $(n=121)$. In the receiver operating characteristic analysis performed for the neutrophil/ lymphocyte ratio, the cut-off point was found to be 2.25 (area under the curve $=0.71,95 \%$ confidence interval: $0.622-0.816$, sensitivity: $66.7 \%$, selectivity: $73.6 \%$ ). Conclusion: Neutrophil/lymphocyte ratio, which is one of the hematological parameters, can be used as an auxiliary tool for examination and imaging methods in the diagnosis of stage I germ cell testicular tumor, which is considered to be an early stage.
\end{abstract}

Keywords: Cancer, diagnosis, lymphocyte, neutrophil, testis

\section{Introduction}

Although testicular tumors are not very common, they are important because they are seen at a young age. Although tumor markers such as alpha fetoprotein (AFP), human chorionic gonadotropin (hCG), lactate dehydrogenase (LDH) are used in the clinical practice of testicular tumors in which prolonged survival can be achieved with early diagnosis; cheaper and useful diagnostic and follow-up methods are being investigated (1).

There is a close relationship between inflammatory response and tumorigenesis and tumor progression (2). Some of the systemic inflammatory response indicators that can be measured with hematological parameters are used in diagnosis and to predict the prognosis in different malignancies $(3,4)$. Studies on the neutrophil/lymphocyte ratio (NLR) in urothelial tumors (mostly urothelial carcinomas) have been conducted, and it has been shown that NLR elevation is associated with poor prognosis in most studies $(5,6,7)$. Also; it has been reported that parameters related to platelets involved in the inflammatory process of malignant tumors, such as platelet count, thrombocyte/ lymphocyte ratio (PLR), mean platelet volume can also be used as biomarkers in various tumors (8).

There is a lack of information about the relationship between germ cell tumors (GCT), which constitute $95 \%$ of testicular tumors, with hematological parameters commonly used in other tumors. In this study, it was aimed to determine the value of hematological parameters used in other malignancies in the diagnosis of localized germ cell testicular tumor.

Cite this article as: Kartal I, Çimen S, Özenç G, Kokurcan A, Baylan B, Karakoyunlu N, Yiğitbaşı O, Yalçınkaya F. The Auxiliary Role of Hematological Parameters in Diagnosing Localized Germ Cell Testicular Tumor. Bull Urooncol 2020;19(4):210-214

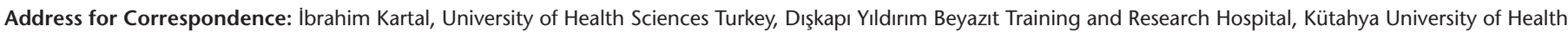
Sciences Turkey, Evliya Çelebi Training and Research Hospital, Clinic of Urology, Ankara, Kütahya, Turkey

Phone: +90 5556298424 E-mail: igk84@hotmail.com ORCID-ID: orcid.org/0000-0002-2313-3522 Received: 14.10.2019 Accepted: 26.11.2019 


\section{Materials and Methods}

After the study was approved by the local ethics committee, the data of patients who underwent radical orchiectomy and diagnosed as having localized GCT between January 2015 and March 2019 and those who underwent varicocelectomy within the same period were evaluated retrospectively. Patients with localized GCT up to pTx NO MO (stage I) and patients who underwent varicocelectomy within the same period and were assigned as the control group were included in the study. Computed tomography or magnetic resonance imaging and tumor markers were used in the staging of patients with germ cell testicular tumors. The patients were staged according to the 2009 tumor-node-metastases classification of the International Union Against Cancer. Patients with non-germ cell testicular tumor, active infection or chronic inflammatory disease, patients using anticoagulants, taking hormonal therapy in the last year, and patients with hematological disorders were excluded from the study.

Age, body mass index, tumor size and preoperative AFP, hCG, and $\mathrm{LDH}$ values of patients with germ cell testicular tumors were recorded. Among the hematological parameters; neutrophil, lymphocyte, platelet counts and mean platelet volume were measured from preoperatively collected peripheral blood samples. These values and ratios were compared between patients with localized GCT and patients in the control group to determine the diagnostic values of these parameters in germ cell testicular tumor.

Receiver operating characteristic (ROC) curve was created for NLR and PLR to evaluate them in the diagnosis of germ cell testicular tumor. The cut-off point value of NLR was calculated with the area under the curve (AUC). Sensitivity, selectivity, positive and negative predictive values of the NLR were determined.

\section{Statistical Analysis}

Whether the distribution of continuous variables was normal or not was determined by Kolmogorov-Smirnov test. Levene test was used to evaluate the homogeneity of variances. When appropriate, descriptive statistics for continuous variables were expressed as mean \pm standard deviation or median ( $1^{\text {st }}$ quarter to $3^{\text {rd }}$ quarter). The number of patients and percentages were used for categorical data. Student t-test was applied to numerical data with normal distribution, and non-parametric Mann-Whitney $U$ test was applied to numerical data without normal distribution. Categorical data were analyzed using the chi-square test with continuity correction. ROC curve analyzes for NLR and PLR, which could be used as determinants in the diagnosis of localized GCT, were performed to find the cut-off points. The Youden index method was used to find the best cutoff point of the NLR. Sensitivity, specificity, positive and negative predictive values and accuracy rates at the best cut-off point for NLR and neutrophil percentage/lymphocyte percentage ratio [NLR (\%)] were calculated. Odds ratios and 95\% confidence intervals $(\mathrm{Cl})$ were also calculated for each independent variable. Data analysis was performed in the "SPSS for Windows 17.0" package program (IBM Corporation, Armonk, NY, USA). Results for $p<0.05$ were considered statistically significant.

\section{Results}

Descriptive statistics of demographic and preoperative clinical data of patients with localized GCT in the study group are given in Table 1. In the evaluation performed in terms of preoperative hematological parameters among the groups diagnosed as having localized GCT and varicocelectomy, it was found that the median neutrophil count and neutrophil percentage of the localized GCT group were statistically significantly higher than the varicocelectomy group $(p<0.001$ and $p<0.001)$. While there was no statistically significant difference between the groups in terms of lymphocyte counts $(p=0.244)$, the percentage of lymphocytes in the localized GCT group was found to be statistically significantly lower than the varicocelectomy group $(p<0.001)$. The median NLR of the localized GCT group was statistically significantly higher than the varicocelectomy group $(p<0.001)$ (Figure 1). Additionally, the median NLR (\%) ratio of the localized GCT group was found to be statistically significantly higher than the varicocelectomy group $(p<0.001)$ (Table 2$)$.

In the ROC analysis of NLR and PLR in both groups, the AUC of the NLR was found to be statistically significant in distinguishing the two groups (AUC: 0.719, 95\% Cl: 0.622-0.816 and $\mathrm{p}<0.001$ ) (Figure 2). The best cut-off point of NLR in distinguishing the

Table 1. Demographic and preoperative clinical data of patients with localized germ cell testicular tumor in the study group

\begin{tabular}{|c|c|c|}
\hline & $\mathrm{n}=39$ & Minimum-maximum \\
\hline Age & $33.2 \pm 10.6$ & $17-60$ \\
\hline Body mass index $\left(\mathrm{kg} / \mathrm{m}^{2}\right)$ & $24.4 \pm 3.6$ & $18.5-32.9$ \\
\hline Tumor size $(\mathrm{cm})$ & 4.9 & $1.0-12.0$ \\
\hline \multicolumn{3}{|l|}{ Pathology } \\
\hline Seminoma & $17(43.5 \%)$ & - \\
\hline $\begin{array}{l}\text { Non-seminomatous } \\
\text { germ cell tumor }\end{array}$ & $22(56.5 \%)$ & - \\
\hline $\operatorname{AFP}(\mathrm{U} / \mathrm{mL})$ & $140.6 \pm 433.1$ & $0.6-2514.5$ \\
\hline $\mathrm{hCG}(\mathrm{mlU} / \mathrm{mL})$ & $166.8 \pm 425.2$ & $0.5-1806.0$ \\
\hline LDH (U/L) & $234.9 \pm 96.4$ & $140.0-615.0$ \\
\hline
\end{tabular}

AFP: Alpha fetoprotein, hCG: Human chorionic gonadotropin, LDH: Lactate dehydrogenase

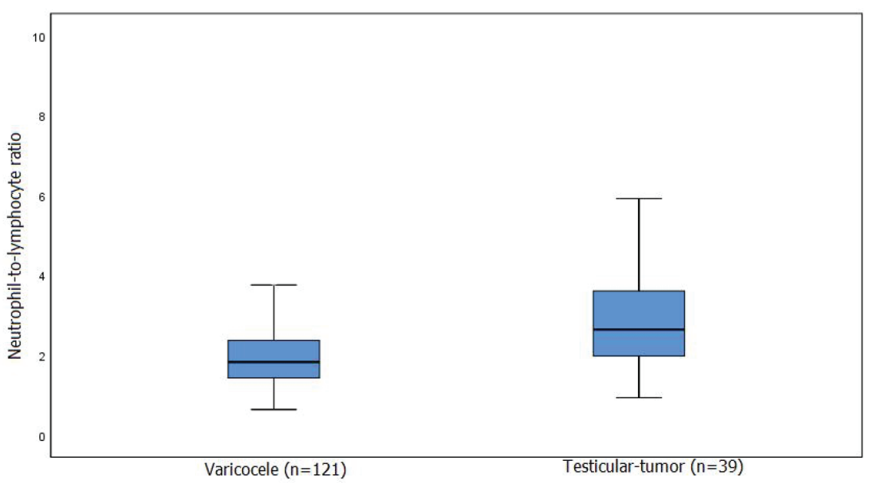

Figure 1. Box-plot graphs of the neutrophil/lymphocyte ratios of the localized germ cell testicular tumor group and the control group (patients who underwent varicocelectomy) 


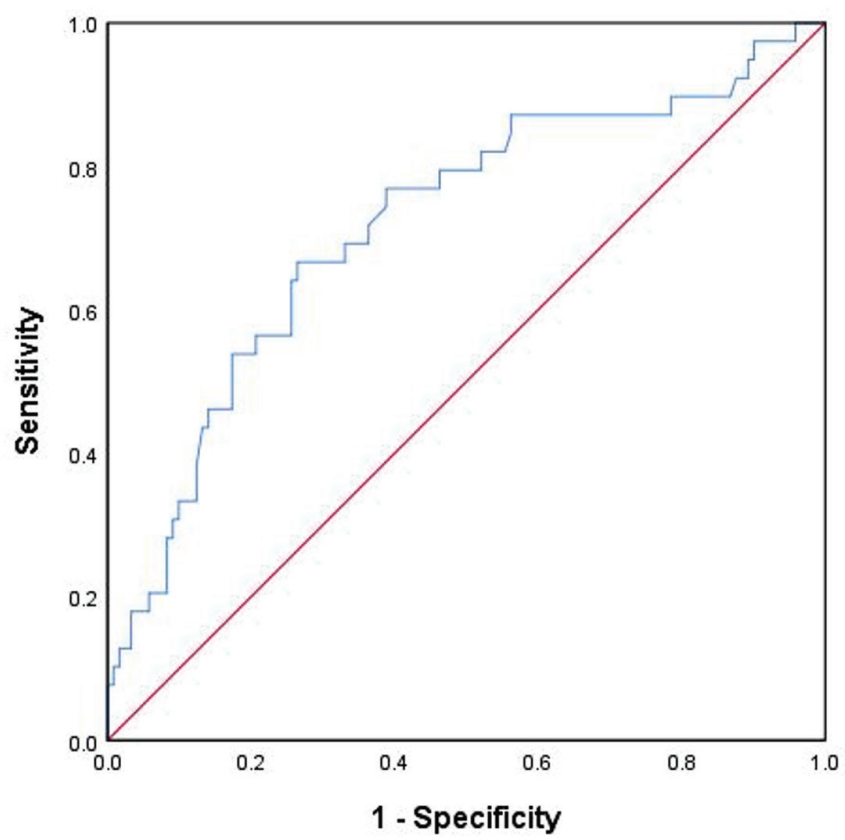

Figure 2. Receiver operating characteristics curve for neutrophil/lymphocyte ratio in patients with localized germ cell testicular tumor

Table 2. Preoperative hematological parameters of the localized germ cell testicular tumor group and the control group (patients who underwent varicocelectomy)

\begin{tabular}{|c|c|c|c|}
\hline & $\begin{array}{l}\text { Germ cell } \\
\text { testicular } \\
\text { tumor }(n=39)\end{array}$ & $\begin{array}{l}\text { Varicocele } \\
(\mathrm{n}=121)\end{array}$ & $\mathbf{p}$ \\
\hline Neutrophil count $\left(10^{3} / \mathrm{uL}\right)$ & $\begin{array}{l}5.6 \\
(4.3-7.2)\end{array}$ & $\begin{array}{l}4.1 \\
(3.3-5.1)\end{array}$ & $<0.001^{\mathrm{a}}$ \\
\hline Neutrophil percentage (\%) & $\begin{array}{l}65.8 \\
(58.5-72.7)\end{array}$ & $\begin{array}{l}57.4 \\
(52.1-62.9)\end{array}$ & $<0.001^{\mathrm{a}}$ \\
\hline Lymphocyte count (103/uL) & $\begin{array}{l}2.1 \\
(1.8-2.6)\end{array}$ & $\begin{array}{l}2.2 \\
(1.9-2.6)\end{array}$ & $0.244^{\mathrm{a}}$ \\
\hline Lymphocyte percentage (\%) & $25.3 \pm 8.0$ & $31.4 \pm 7.2$ & $<0.001^{\mathrm{b}}$ \\
\hline Platelet count $\left(10^{3} / \mathrm{uL}\right)$ & $269.7 \pm 65.3$ & $253.6 \pm 52.7$ & $0.121^{b}$ \\
\hline Mean platelet volume (fL) & $8.2 \pm 0.87$ & $8.3 \pm 0.92$ & $0.536^{\mathrm{b}}$ \\
\hline Hemoglobin value (g/dL) & $15.5 \pm 1.25$ & $15.6 \pm 0.99$ & $0.526^{\mathrm{b}}$ \\
\hline Neutrophil/lymphocyte ratio & $\begin{array}{l}2.6 \\
(2.0-3.6)\end{array}$ & $\begin{array}{l}1.8 \\
(1.4-2.4)\end{array}$ & $<0.001^{\mathrm{a}}$ \\
\hline $\begin{array}{l}\text { Neutrophil } \\
\text { percentage/lymphocyte } \\
\text { percentage ratio (\%) }\end{array}$ & $\begin{array}{l}2.7 \\
(1.9-3.7)\end{array}$ & $\begin{array}{l}1.8 \\
(1.4-2.4)\end{array}$ & $<0.001^{\mathrm{a}}$ \\
\hline Platelet/lymphocyte ratio & $\begin{array}{l}124.5 \\
(101.7-158.3)\end{array}$ & $\begin{array}{l}112.2 \\
(90.5-137.9)\end{array}$ & $0.051^{\mathrm{b}}$ \\
\hline \multicolumn{4}{|c|}{$\begin{array}{l}\text { a: Mann-Whitney } \mathrm{U} \text { test, }{ }^{\mathrm{b}} \text { : Student's } \mathrm{t} \text {-test, descriptive statistics are expressed } \\
\text { as the median ( } 1^{\text {st }} \text { quarter- } 3^{\text {rd }} \text { quarter). Data are shown as mean } \pm \text { standard } \\
\text { deviation }\end{array}$} \\
\hline
\end{tabular}

two groups was calculated as 2.2532. The sensitivity of NLR at this point was $66.7 \%$, selectivity $73.6 \%$, positive and negative predictive values were $44.8 \%$ and $87.3 \%$, respectively and the diagnostic accuracy rate was $71.9 \%$.

Likewise, the area under the ROC curve for NLR (\%) was found to be statistically significant in distinguishing the groups (AUC:
0.715, 95\% Cl: $0.616-0.814$ and $\mathrm{p}<0.001)$. The best cut-off point for NLR (\%) was calculated as 2.5452 and at this point, sensitivity was $56.4 \%$, selectivity was $82.6 \%$, positive predictive value was $51.2 \%$, negative predictive value was $85.5 \%$ and diagnostic accuracy was $76.3 \%$.

The area under the ROC curve of PLR was not found to be statistically significant in distinguishing between localized GCT and varicocelectomy groups (AUC: $0.604,95 \% \mathrm{Cl}$ : 0.499-0.709 and $p=0.051$ ) (Table 3).

\begin{tabular}{|c|c|c|c|}
\hline & NLR & NLR (\%) & PLR \\
\hline Area under the curve & 0.719 & 0.715 & 0.604 \\
\hline $95 \%$ confidence interval & $0.622-0.816$ & $0.616-0.814$ & $0.499-0.709$ \\
\hline$p$-value ${ }^{a}$ & $<0.001$ & $<0.001$ & 0.051 \\
\hline Best cut-off point & $>2.2532$ & $>2.5452$ & - \\
\hline Sensitivity [TP/(TP+FN)] & $\begin{array}{l}26 / 39 \\
(66.7 \%)\end{array}$ & $\begin{array}{l}22 / 39 \\
(56.4 \%)\end{array}$ & - \\
\hline Selectivity [TN/(TN+FP)] & $\begin{array}{l}89 / 121 \\
(73.6 \%)\end{array}$ & $\begin{array}{l}100 / 121 \\
(82.6 \%)\end{array}$ & - \\
\hline $\mathrm{PPV}[\mathrm{TP} /(\mathrm{TP}+\mathrm{FP})]$ & $\begin{array}{l}26 / 58 \\
(44.8 \%)\end{array}$ & $\begin{array}{l}22 / 43 \\
(51.2 \%)\end{array}$ & - \\
\hline $\mathrm{NPV}[\mathrm{TN} /(\mathrm{FN}+\mathrm{TN})]$ & $\begin{array}{l}89 / 102 \\
(87.3 \%)\end{array}$ & $\begin{array}{l}100 / 117 \\
(85.5 \%)\end{array}$ & - \\
\hline Accuracy $[(\mathrm{TP}+\mathrm{TN}) /(\mathrm{N})]$ & $\begin{array}{l}115 / 160 \\
(71.9 \%)\end{array}$ & $\begin{array}{l}122 / 160 \\
(76.3 \%)\end{array}$ & - \\
\hline Odds ratio & 5.563 & 6.162 & - \\
\hline $95 \%$ confidence interval & 2.553-12.119 & $2.801-13.560$ & - \\
\hline$p$-value ${ }^{b}$ & $<0.001$ & $<0.001$ & - \\
\hline \multicolumn{4}{|c|}{$\begin{array}{l}\text { a: Receiver operating characteristics analysis, b: Chi-square test with continuity } \\
\text { correction, TP: True positive, FN: False negative, TN: True negative, FP: False } \\
\text { positive, PPV: Positive predictive value, NPV: Negative predictive value, N: Total } \\
\text { number of patients, NLR: Neutrophil/lymphocyte ratio, PLR: Platelet/lymphocyte } \\
\text { ratio }\end{array}$} \\
\hline
\end{tabular}

\section{Discussion}

Systemic inflammation varies according to peptides secreted from tumor cells, the inflammatory response of the tumor cells, and the type and extent of the tumor (9). The relationship between tumor and immune system has a very important effect on the clinical course of patients. Immune system cells, on the one hand, fight the tumor, on the other hand, cause the activation of malignant cells with the growth factors they produce, and increase their invasive capacity and metastatic capacity (10). It has been determined that markers such as C-reactive protein, neutrophil and platelet count that measure systemic inflammatory response are independent prognostic factors in many types of cancer (11). NLR and PLR ratios are very suitable parameters for evaluating the inflammatory response with their easy measurement and low cost $(12,13)$.

Studies on testicular tumors and inflammatory response generally evaluated the relationship between prognosis and metastasis 
and response (14). The groups in the studies were generally heterogeneous, and there was no clear information about the use of NLR and about a standard cut-off value in the diagnosis of stage I testicular tumors. Our study included only patients with stage I GCT. Since other studies included patients with advanced stage testicular tumors, our study may have provided a clue for detecting patients in the localized stage of testicular tumors where early diagnosis was important. Since patients with stage I disease were included in the study group and the progression was low in this group, the relationship between inflammatory response and prognosis was not evaluated.

When the literature is reviewed, there are different opinions about the relationship between NLR and the stage and prognosis of the testicular tumor. Jankovich et al. (15) found that the NLR was significantly higher in the metastatic patient group with GCT in their study and reported that the NLR could give an idea about the stage of the disease when a diagnosis of testicular tumor was made. In contrast to this information, in a recently published study, it was reported that there was no relationship between preoperative NLR and stage, progression-free survival and cancer-specific survival (16). Interestingly, unlike these two studies, Imamoglu et al. (17) reported that the relationship between NLR and metastasis was limited only to seminomas. We looked at the relationship between inflammatory response and testicular tumor from a different perspective because of the inconsistency between studies, and the increased ease of access to information and awareness of patients in this age group. We evaluated the inflammatory response in terms of stage I which was the most frequently observed stage in testicular tumors at the time of diagnosis. Of course, we tried to homogenize our study with some exclusion criteria, taking into account the non-specific inflammatory response and its increase in many patients. However, it was clear that NLR could not be used as the primary diagnostic method in the diagnosis of testicular tumors. However, our results supported that in case of doubt, with its easy measurement and cost-effectiveness, NLR could be used as an auxiliary tool for diagnosis even in low tumor volumes, with its 2.25 cut-off point and relatively high sensitivity and selectivity.

There is no consensus in the literature regarding the relationship between PLR and the diagnosis, stage and prognosis of testicular tumor. Gokcen et al. (18) found a significant difference in terms of PLR between patients with testicular tumor at different stages and patients who underwent varicocelectomy. In another study, it was reported that PLR could only be an indicator for metastasis in non-seminomatous GCT (17). However, there are still doubts about the use of PLR in all malignancies, not just in testicular tumors (19). In our study, it was determined that the use of PLR for early diagnosis of testicular tumor had no value. However, studies evaluating the relationship of PLR with the prognosis of testicular tumor are needed.

\section{Study Limitations}

The most important limitations of our study were that it was a single center and retrospective study, and it included relatively a small number of patients. In addition, although surgical intervention was performed in patients without evidence of infection and routine preoperative evaluation was performed by urologists and anesthesiologists; the failure to evaluate preoperative acute phase reactants could be considered as a limiting factor.

\section{Conclusion}

Hematological parameters NLR; with its easy measurement and cost advantage, it can be used as an auxiliary tool to the clinician with a standard cut-off value even in the diagnosis of stage I patients with good prognosis in testicular tumors where early diagnosis is important even if not used primarily.

\section{Acknowledgements}

Publication: The results of the study were not published in full or in part in form of abstracts.

Contribution: There is not any contributors who may not be listed as authors.

Conflict of Interest: No conflict of interest was declared by the authors.

Financial Disclosure: The authors declared that this study received no financial support.

\section{Ethics}

Ethics Committee Approval: This study was approved by the University of Health Sciences Turkey, Dışkapı Yıldırım Beyazıt Training and Research Hospital Clinical Research Board. (decision no: 72/01, date: 23.09.2019)

Informed Consent: Written informed consent was obtained from patients who participated in this study.

Peer-review: Externally and internally peer-reviewed.

\section{Authorship Contributions}

Concept: I.K., S.Ç., A.K., N.K., B.B., F.Y., Design: I.K., S.Ç., A.K., N.K., B.B., F.Y., Data Collection or Processing: İ.K., G.Ö., A.K., B.B., Analysis or Interpretation: I.K., A.K., O.Y., Literature Search: I.K., A.K., B.B., Writing: I..K., S.Ç., F.Y.

\section{References}

1. Stevenson SM, Lowrance WT. Epidemiology and Diagnosis of Testis Cancer. Urol Clin North Am 2015;42:269-275.

2. Mantovani A. Molecular Pathways Linking Inflammation and Cancer. Curr Mol Med 2010;10:369-373.

3. Gregory AD, Houghton AM. Tumor-associated neutrophils: new targets for cancer therapy. Cancer Res 2011;71:2411-2416.

4. Mantovani A, Allavena P, Sica A, et al. Cancer-related inflammation. Nature 2008;454:436-444.

5. Marchioni $M$, Primiceri $G$, Ingrosso $M$, et al. The Clinical Use of the Neutrophil to Lymphocyte Ratio (NLR) in Urothelial Cancer: A Systematic Review. Clin Genitourin Cancer 2016;14:473-484.

6. Altan $M$, Haberal HB, Akdogan B, et al. A critical prognostic analysis of neutrophil-lymphocyte ratio for patients undergoing nephroureterectomy due to upper urinary tract urothelial carcinoma. Int J Clin Oncol 2017;22:964-971.

7. Gökçe Mi, Hamidi N, Esen B, et al. Evaluation of Role of Inflammatory Markers for the Prediction of Recurrence on Pathologic T1a Clear Cell Renal Cell Cancer Patients. Üroonkoloji Bülteni 2016;15:18-21.

8. Zhou $X$, Du $Y$, Huang $Z$, et al. Prognostic value of PLR in various cancers: a meta-analysis. PLoS One 2014;9:e101119. 
9. McDowell SAC, Quail DF. Immunological Regulation of Vascular Inflammation During Cancer Metastasis. Front Immunol 2019; 10:1984.

10. Kusumanto YH, Dam WA, Hospers GA, et al. Platelets and granulocytes, in particular the neutrophils, form important compartments for circulating vascular endothelial growth factor. Angiogenesis 2003;6:283-287.

11. Roxburgh CS, Crozier JE, Maxwell F, et al. Comparison of tumourbased (Petersen Index) and inflammation-based (Glasgow Prognostic Score) scoring systems in patients undergoing curative resection for colon cancer. Br J Cancer 2009;100:701-706.

12. Kızılay F, Şimşir A. Can High Preoperative Neutrophil-lymphocyte Ratio Predict the Recurrence and Progression Risk of Non-muscleinvasive Bladder Tumors? Bull Urooncol 2019;18:40-45.

13. Yuksel $\mathrm{OH}$, Verit $A$, Sahin A, et al. White blood cell counts and neutrophil to lymphocyte ratio in the diagnosis of testicular cancer: a simple secondary serum tumor marker. Int Braz J Urol 2016;42:53-59.

14. Chovanec M, De Giorgi U, Mego M. Immune-Related Concepts in Biology and Treatment of Germ-Cell Tumors. Adv Urol 2018;2018:1-6.
15. Jankovich M, Jankovichova T, Ondrus D, et al. Neutrophil-tolymphocyte ratio as a predictor of preoperative tumor staging in testicular germ cell tumors. Bratisl Lek Listy 2017; 118:510-512.

16. Bolat $D$, Aydogdu $O$, Polat $S$, et al. Predictive value of preoperative neutrophil-to-lymphocyte ratio on the prognosis of germ cell testicular tumors. Turk J Urol 2017;43:55-61.

17. Imamoglu Gl, Eren T, Baylan B, et al. May High Levels of Systemic Immune-Inflammation Index and Hematologic Inflammation Markers Suggest a Further Stage in Testicular Tumours? Urol Int 2019;103:303-310.

18. Gokcen K, Dundar G, Gulbahar H, et al. Can routine peripheral blood counts like neutrophil-to-lymphocyte ratio be beneficial in prediagnosis of testicular cancer and its stages? J Res Med Sci 2018;23:64.

19. Wang J, Liu Y, Zhang N, et al. Prognostic role of pretreatment platelet to lymphocyte ratio in urologic cancer. Oncotarget 2017;8:70874-70882. 